\title{
Time without Rate
}

\section{Takeshi Sakon}

\begin{tabular}{|c|l|}
\hline Citation & Philosophical Papers, 45(3): 471-496 \\
\hline Issue Date & $2016-10-25$ \\
\hline Type & Journal Article \\
\hline Textversion & Author \\
\hline Relation & $\begin{array}{l}\text { This is an Accepted Manuscript of an article published by Taylor \& Francis in } \\
\text { Philosophical Papers on 25/10/2016, available online: } \\
\text { https://doi.org/10.1080/05568641.2016.1245838 }\end{array}$ \\
\hline DOI & $10.1080 / 05568641.2016 .1245838$ \\
\hline
\end{tabular}

\author{
Self-Archiving by Author(s) \\ Placed on: Osaka City University
}




\section{Time without Rate}

\section{Takeshi SAKON}

A Lecturer at Philosophy,

Graduate School of Literature and Human Sciences,

Osaka City University

E-mail: sakon@lit.osaka-cu.ac.jp 


\begin{abstract}
There is a lingering objection to the idea of the passage of time. Roughly speaking, the argument runs as follows: (i) if time passes, its passage must occur at some rate, but (ii) there is no such rate; hence, the passage of time is a myth. While some philosophers try to reject premise (ii), I wish to challenge the first premise by arguing that time may pass with or without a rate. My argument addresses two cases, one that identifies the passage of time with changes in things and one that does not. I call the former view 'the Priorian passage theory', and the latter view 'the pure passage theory'. I argue that each dynamic view of time is immune to the rate argument. Further, I suggest a possible extension of the Priorian passage theory, in which the passage of time is identified with the pure persistence of things.
\end{abstract}

KEYWORDS: Passage of Time; Rate Argument; Changes in Things; Pure Passage; Persistence of Things 


\section{Rate Argument against the Passage of Time}

There is a lingering objection to the idea of the passage of time. Smart (1949), Williams (1951) and others have argued that the passage of time is a myth. Recently, Olson (2009) presented one such argument. Roughly speaking, it is as follows: (i) if time passes, the passage must occur at some rate, but (ii) there is no such rate; hence, the passage of time is a myth. Let us call this the rate argument. Assuming that (i) is true, Olson asks how fast time passes and infers that only one answer seems possible: time passes at one second per second. According to Olson, however, '[o]ne second per second is one second divided by one second. And when you divide one second by one second, you get one. Not one of anything, just one. ... And one is not a rate of change' (Olson 2009: 5). If Olson is right, it is wrong to say that time passes. ${ }^{1}$

In reply, Phillips (2009) has questioned Olson's notion of rate:

... [O]ne second per second is not one second divided by one second, and it is not equal to one. One second per second is a ratio of time to unit time, a relation between two amounts of time, whereas neither one second divided by one second nor one is a ratio or relation of quantities. (Phillips 2009: 503)

While Phillips has cast doubt on premise (ii) by saying that Olson's argument does not

\footnotetext{
1 Price (1996) and Van Inwagen (2009) have also offered the rate argument in the same form.
} 
stand because of its failure to show that one second per second is not a genuine rate, I wish to challenge the other premise in the present paper: if time passes, the passage must occur at some rate. ${ }^{2}$ To put it more clearly, I argue that time may pass with or without a rate.

The question of how fast time passes has intrigued many people because it appears that there is a strong conceptual connection between time passing and its passing at some rate. ${ }^{3}$ The main purpose of the current paper is to break such a conceptual link. Success in this attempt will not only provide us with a reason for rejecting the rate argument but will also shed some light on the nature of time. If I am correct in saying that time may pass with or without a rate, it will mean that the rate argument, which rests upon the very question of how fast time passes, is irrelevant to the debate between the dynamic view of time (the view that time passes in some sense) and the static view of time (the view that time does not pass in any sense). It is then far from trivial to see that the passage of time (at least in its essence) need not involve the notion of rate.

2 In what follows, I do not question whether Phillips can really succeed in defeating the rate argument. For discussions relevant to the issue, see Maudlin (2007), Raven (2011), Skow (2012a) and Tallant (2010). Recently, Mazzola (2014) has also cast doubt on premise (i). Whether his attempt succeeds or not, I argue differently here.

3 There may be another motivation behind the question: experience may also provide such a motivation. We sometimes describe our experience by saying that time seems to go fast or slowly, and that may prompt the question of what it would be for this to be objectively so. I cannot address this interesting question about temporal phenomenology due to the space constraints of this paper. 
The passage of time may or may not be identified with changes in things, meaning physical phenomena, including what we are doing and what is going on around us. I call the view that the passage of time is nothing but changes in things 'the Priorian passage theory', and the view that the passage of time is something more than or independent of changes in things, 'the pure passage theory' ${ }^{4}$ Consequently, the paper is divided into two parts, each corresponding to the above viewpoints. In section 2 , I show that the Priorian passage theory is immune to the Olson-style rate argument, because there is a clear sense in which time may pass, whether or not it has a particular rate. In section 3 , I argue that the pure passage theory is also immune to the rate argument because time may pass whether or not we are able to ask meaningfully how fast it passes. In section 4, I suggest a possible extension of the Priorian passage theory, according to which the passage of time should be identified with the pure persistence of things rather than with their qualitative changes.

\footnotetext{
${ }^{4}$ One might associate the distinction between the Priorian view and the pure passage view with other distinctions in philosophy of time. I take it that the Priorian theory is close to what is sometime called the Aristotelian view (or the relational theory of time), according to which the concept of time is derived from changes in things, while the pure passage theory may appear close to what is called the Newtonian view (or the absolute theory of time), according to which the temporal dimension is independent of changes in things. However, neither theory that we discuss is just Aristotelian or Newtonian: it could be properly called a dynamic Aristotelian or Newtonian theory respectively because it claims that time should really pass in some sense. A further examination of this association is beyond the scope of the present paper.
} 


\section{Priorian Passage Theory}

In this section, I consider what I call the Priorian passage theory (2.1) and show how the rate argument fails to pose a serious objection to the theory (2.2). Although it is arguable whether the theory is what Prior actually has in mind, I do believe that it is a minimal form of his view. I contemplate its possible extension below in section 4 , by way of addressing a potential problem that lurks in the (naive) Priorian passage theory.

\subsection{Real Changes in Things}

A. N. Prior (1962) asserts that the passage of time is just a metaphor, which nevertheless expresses an undeniable truth. In his view, it is wrong to take the metaphor literally and reify the passage of time as the movement of the present through the temporal dimension, or the transformation of future events into past events. Nevertheless, the metaphor of the passage of time suggests some truth: things do undergo real changes through time. For instance, a poker can undergo a change from being hot to cold, or vice versa. If I understand his view correctly, Prior says not just that things have different properties at different times but also that things have certain properties simpliciter and undergo changes in those properties. Such changes should be described in tensed terms: when the poker is hot, it will be cold, and when it is cold, it was hot. Thus, Prior holds that the passage of time is nothing more than real changes in things, which constitute the dynamic aspect of the world.

Opponents of Prior's views include eternalists, who think that the world should be described in tenseless terms. They also have their own ways of understanding 
changes in things-but only at the cost of making dynamic tensed facts into static tenseless facts. Suppose that $\mathrm{X}$ undergoes an intrinsic change from being $\mathrm{F}$ to not $\mathrm{F}$. The question we need to ask is how it is possible for $\mathrm{X}$ to be both $\mathrm{F}$ and not $\mathrm{F}$ tenselessly. Endurantist eternalists typically answer that things can undergo changes in relation to different times, but facts about those relational changes hold true at any time. For instance, if a poker is hot at time $t$ and cold at the different time $t^{*}$, its being hot at $t$ and cold at $t^{*}$ holds true at any time. ${ }^{5}$ In contrast, Perdurantist eternalists usually say that changes are mere temporal variations constituted by different temporal parts at different times, but facts about those temporal variations themselves are changeless. For instance, if a poker has a permanently hot temporal part at $\mathrm{t}$ and a permanently cold temporal part at $t^{*}$, nothing undergoes any intrinsic change through time. In either case, persisting things cannot really change in the way Prior thinks they do. ${ }^{6}$ It is widely accepted that there is a significant disagreement between Prior and his opponents on the issue of real

\footnotetext{
5 The claim that things have properties only in relation to times may seem unpalatable in itself. Ordinarily, we do not think that all cases of property possession are time-relative and can at least make sense of the idea that things have properties simpliciter. Following Prior's line of thought, one should naturally assume that the proposition that the poker is hot can also be true or false simpliciter: propositions can undergo changes in absolute truth values through time. In my view, this is a significant disagreement between Prior and his rival theorists. We need not go into detail here, however, because the present purpose is to show that the Priorian passage theory is immune to the rate objection.

6 This relates to the so-called problem of temporal intrinsics. For relevant discussion, see Hinchliff (1996) and Merricks (1994).
} 
changes in things, but what is more important for our purpose is whether the rate argument gives us a good reason to reject Prior's dynamic view of time in favour of eternalism. I argue that it does not.

In short, Prior claims that the passage of time consists in real changes in things, and this claim involves the negation and denial of both eternalism and the existence of independent pure passage. Let us call this view the Priorian passage theory. In this theory, to ask how fast time passes (if this question makes sense at all) is just to ask how fast a given thing changes compared to various changes in things because the passage of time is nothing more than changes in things. (There may be objections from proponents of other views on time, but they are irrelevant in the present context. For Priorian passage theorists, those two questions should be identical.) If your wristwatch undergoes normal physical changes and therefore counts as indicating the passage of time, we may ask, for instance, how fast the big hand on the watch goes round compared to that on mine or on other physical clocks that exhibit more reliable cyclic processes. ${ }^{7}$ One could ask this question however boring it may be.

\footnotetext{
${ }^{7}$ How should we understand the notion of reliability, given that there is no independent passage of time? I say that reliability here is a relative notion. Cyclic process A is more reliable than another cyclic process $\mathrm{B}$ if there exists another standard cyclic process $\mathrm{C}$ with more accurate accordance with A than B. One can also question the reliability of $\mathrm{C}$, and there may be no guarantee of the existence of an absolutely reliable cyclic process in the Priorian passage theory. Further on in the paper, I suggest that the situation differs in the pure persistence theory, a possible extension of the Priorian passage theory. For temporal metrology in scientific practice, see Tal (2011).
} 


\subsection{A Failure of the Rate Argument: Time Passes When Things Change}

The Priorian passage theory is immune to the rate objection because things can change with or without a rate. Consider the following imaginary situation. In a world, things that exhibit irregular movements suddenly stop. Then, most reliable physical clocks stop one by one, and only two working clocks remain. At this stage, it still seems possible to ask how fast time passes meaningfully. An answer can be given as the rate of change in one clock as compared to the changes in the other clock, or vice versa. ${ }^{8}$ Later, when one of the clocks stops, the other continues working. (Let us assume that the whole universe also stops expanding and therefore cannot be used as a global clock.) In this situation, there is no physical change except in the working clock, with respect to which a rate of change should be given. Let us now ask how fast time passes. If we agree with Phillips that the rate of change to itself is genuine, then we can say that time passes at the rate of one second (according to the clock's time) per second (in the same clock's time). However, if we agree with Olson that any rate of change to itself is not a rate at all, then

\footnotetext{
${ }^{8}$ Suppose that the second hand on Clock 1 moves one notch every time Clock 2 has moved two notches. What then is the answer to 'How fast does time pass'? Is it 'two seconds per second' or 'half a second per second'? If both clocks are equally reliable, it is just a matter of stipulation which clock we take as a standard. We can either say 'two seconds* per second' or 'half a second per second*', where one second is defined as one notch on Clock 1 and one second* as that on Clock 2. Here we deal with two different time units defined by two different (but equally reliable) physical clocks, despite the constant rate of change.
} 
there would be no answer. Does this mean that there is no change and therefore that time does not pass? Clearly not, as one clock is still working!

The solitary clock undergoes physical changes whether one second per second (both measured by the same clock) is a genuine rate or not. Even if it does not count as a genuine rate, this never prevents the clock from undergoing a cyclic process. As long as the clock is working, time may pass, according to the Priorian passage theory. (If one objects that a usual clock has many moving parts, Tallant provides a nicer example in which 'the only change that occurs is the oscillation of a single caesium atom' (2010: 138). In such a case, there would be no rate at which the change occurs if we define a rate as a relation that one quantity bears to another.) Prior himself has made a similar remark in the following passage:

... I am now exactly a year older than I was a year ago; it has taken me exactly a year to become a year older; and quite generally, the rate of this change is one time-unit per time-unit... If a 'rate' of change is a ratio between something else and a time-interval, there is no rate at which my age changes; if it is just a ratio between something (whether a different something or the same something) and a time-interval, my age changes at the rate stated above; and in any case I become a year older every year (there are such things as birthdays), whether this be called a 'rate' of a year per year or not. (Prior 1958: 244) 
The point will be clearer if we replace Prior's birthday with each revolution of the big hand on our imaginary solitary clock. Whereas the question of how fast Prior is getting older could in principle be answered by comparison to other physical changes, such a comparative answer is by hypothesis impossible in the case of the solitary clock.

Nonetheless, it is true to say that it takes exactly one second (measured by the clock) for one second (measured by the same clock) to pass, whether this be properly called a 'rate' or not. From the Priorian viewpoint, it is just a verbal matter. Even if Olson is right in saying that one second per second is not a genuine rate, one can easily define a new notion of a quasi-rate that allows comparison of one quantity to itself. In any case, if the passage of time is nothing but real changes in things, such as human ageing or the movement of a big hand on a clock, time may pass with or without a rate as long as a thing changes. ${ }^{9}$

I have said that if the passage of time consists in changes in things, whether its passage has a rate is irrelevant in determining its existence. To be certain, eternalists would deny that things can change in the Priorian sense, but this does not imply that the Priorian passage theory is incoherent in itself. More importantly, eternalists should admit that things appear to undergo changes through time even though they reject the Priorian notion of change. Eternalists should say, for instance, that the solitary clock exhibits a normal cyclic process, and I take this as a Moorean fact that no one can deny.

\footnotetext{
9 The discussion here may be considered as giving historical support to Tallant (2010), although he does not cite Prior. He also points out that '[ $t$ ]he mere occurrence of a change does not entail that the change occur at a given rate' (Tallant, 2010: 138).
} 
Once this is admitted, Priorian passage theorists may say, if the theory is feasible at all, that when something changes, time must pass (albeit metaphorically). Of course, discussion will take place between Prior and his rivals over which view of time is correct and whether and how real changes are possible, but here the rate argument has no bearing on the subject at issue.

This illustrates how the rate argument fails to refute the Priorian passage theory. It is suggestive to see what Prior says about Smart's original version of the rate argument:

... I want to argue here that this argument, though it was worth trying once, is really either pedantic or perverse-pedantic if it is meant to show only that all talk of time's flow or passage is figurative, which everyone knows; perverse if it denies the truth which this figure [i.e. all talk of time's flow] is plainly intended to convey, which everyone also knows. (Prior 1958: 244)

As Prior says, the rate argument fails to pose a serious challenge to his view on time. If the argument succeeded, it would refute our beliefs in changes in things altogether, which justify all talk of time's flow.

I conclude that the Priorian passage theory is immune to the rate argument. Before moving on to the next section, however, I should note that Prior's response might invite another problem: if the passage of time is nothing more than changes in things, does it not imply that time cannot pass when nothing changes? Defenders of the 
Priorian passage theory might accept this obnoxious implication, but in the last section, I consider how Priorian passage theorists can cope with this problem. (In that section, I suggest that Prior could accept the notion of non-qualitative changes in things in addition to their qualitative changes. This seems consistent with the first passage cited from Prior.) I now turn to another dynamic view of time, which is distinct from the Priorian passage theory, and argue that it is also defensible against the rate argument.

\section{Pure Passage Theory}

Those dissatisfied with the Priorian passage theory may instead be attracted to the view that, among various changes, there should be a special kind of change called pure passage, which is something more than or independent of changes in things. Note that just positing the independent temporal dimension does not imply the existence of pure passage. It should also have a dynamic aspect: time really passes or flows in some sense. ${ }^{10}$ Let us call this view the pure passage theory.

Although personally I favour the Priorian approach, I try to argue on behalf of pure passage theorists in this section because the main purpose of this paper is not to

${ }^{10}$ It is worth noting how the notion of pure passage differs from that of absolute time. Although pure passage is a kind of external time, absolute time may not have any dynamic aspect. In fact, there are eternalists who also hold the absolute theory of time. Pure passage theorists claim not only that time is independent of any physical processes but also that it has some dynamic aspect that eternalists rule out. The question that we should ask is then whether the rate argument can really succeed in defeating the latter claim. 
defend a certain dynamic view of time but to defuse the efficacy of the rate argument completely. In doing so, we need not go into details about how to flesh out the pure passage theory, but rather it is sufficient to capture some formal features that are necessary for pure passage. (One might reify the idea of pure passage in terms of what Prior denies: the present moving along the temporal dimension or changes in events from being future to past. Markosian (1993) suggests one such view. See also Skow (2011, 2012b) for an elaboration of the pure passage theory. In the following discussion, however, I keep silent on this matter.)

I then argue hypothetically: if pure passage exists, and it has such-and-such formal features, it can avoid the rate argument. I first try to clarify what formal features pure passage is supposed to have based on Markosian's conception of the temporal paradigm (3.1) and then respond to the rate argument and its slightly modified form (3.2) with some reservations on the scope of this response (3.3).

\subsection{Pure Passage as the Temporal Paradigm}

Pure passage is supposed to be the independent temporal dimension of change and cannot be assimilated with any physical process; rather, it is expected to serve as the standard for every rate of change, of which ordinary physical clocks are mere (imperfect) representations. Put in this way, the pure passage theory may be called ‘temporal universalism'. Markosian explains this idea:

... While we have in practice merely compared the rate of one physical 
change to the rate of another, it may seem that we have at least attempted to do something quite different. For just as we are not really interested in the rate of the change of position of the hands on our clock, so we are not, it seems, really interested in the rate of the change of position of the sun; the latter change is also meant to be a stand-in for a more important change, namely, the pure passage of time. (Markosian 1993: 840-1)

According to the pure passage theory, every rate of change should be measured in terms of pure passage because it is supposed to be the standard for every rate of change. When we compare the rate of a physical change to that of the change in the position of the hands on our clock or of the sun, in reality we intend to measure the rate of change in terms of pure passage, even though beings like us do not perceive it directly. We just assume that our clock or the sun is a fairly good stand-in for pure passage. ${ }^{11}$

In this theory, to ask how fast time passes means to compare the rate of pure passage to itself because every rate of change should be measured in terms of pure

11 The meaning of the expression 'a mere stand-in for pure passage' might seem obscure. By definition, pure passage is something more than or independent of physical changes. Thus, a physical change is divorced from pure passage. How, then, could a physical change play the role of an intelligible stand-in for pure passage? What exactly is the sense of 'stand-in' here? I can only answer this question by saying that, at least in ordinary practice, some physical clocks are taken to be approximate to pure passage. Although there is no guarantee that we can find a perfect clock, we may live our lives as if we had such a clock. 
passage. However, it is arguable whether such a comparison is really possible.

Markosian suggests that

$\ldots$ [a]ccording to this view, it does not make sense to ask about the rate of the passage of time, for to do so is to make a category mistake: the answer would have to involve a comparison between the pure passage of time and the pure passage of time, but such an answer would not make sense because the pure passage of time has a unique status among changes - it is the one to which other, normal changes are to be compared. It is the paradigm, and, as such, it alone among changes cannot be measured. (Markosian 1993: 843)

To ask how fast time passes would involve a comparison of pure passage to itself, but Markosian thinks that there is a sense in which such a comparison is impossible because pure passage is the paradigm among various changes. Pure passage cannot be measured because of its special status; therefore, to ask how fast time passes is to make a category mistake. We have no answer because no sensible question has been raised in the first place. Roughly speaking, this is how the rate argument fails, according to Markosian. (Markosian suggests several responses to the rate argument. The above response is just one of them.)

In my view, however, Markosian's reply is not quite convincing because he does not explain fully why and how pure passage has a unique status among other changes. Markosian points out that pure passage 'is the paradigm, and, as such, it alone among 
changes cannot be measured'. To support this claim, he only cites Wittgenstein's analogous remark on the standard metre in Paris. Wittgenstein seems to suggest that the standard metre in Paris is neither one metre long nor not one metre long because of its peculiar role in measuring length. This statement by Wittgenstein invites an unnecessary objection. Olson (2009) complains that the analogy is of no help. Wittgenstein's argument is based on his belief that a statement such as ' $[\mathrm{t}]$ he metre standard $\mathrm{S}$ is one metre long' is a tautology and that tautologies are never true. However, as Olson says, few presently accept Wittgenstein's view of tautologies. How, then, can we amend this flaw in Markosian's argument?

A hint is dropped at the point where the analogy collapses. Kripke (1980) says that Wittgenstein must be wrong because the statement in question is an instance of the contingent a priori. 'The metre standard $\mathrm{S}$ ' is one metre long is knowable a priori because $\mathrm{S}$ is used to fix the reference of the term 'one metre'. Nonetheless, if S had been under a different condition, it would have had a length other than one metre, even at the time of definition. Therefore, the statement is contingent and meaningful in the sense that it is true, but could also be false. While it is necessary that one metre is one metre, it is contingent that $S$ is one metre long. The mere fact that a statement is knowable a priori is not a sign of its being necessary.

Now, compare this with our temporal case. For the sake of argument, let us imagine the clock of pure passage. We then define an 'HOUR' as the amount of time it takes for the big hand on the clock of pure passage to go round and use it solely to 
define a time unit. ${ }^{12}$ Consider the statement that

- it takes one HOUR for the big hand on the clock of pure passage to go round.

If 'one HOUR' is defined in advance, independent of the movement of the hand on the clock, then the temporal statement is no less meaningful than is the statement ' $\mathrm{S}$ is one metre long'. It could take more or less than one HOUR for the big hand to go round. However, in the present hypothesis, the movement of the imaginary clock is pure passage, so it never fails to take exactly one HOUR. Hence, the above statement is an instance of the necessary a priori just as is the statement that one metre is one metre.

One might object that, if the movement of the big hand on the clock of pure passage sped up or slowed down, then the statement in question could also be false and therefore contingent: one HOUR on a particular occasion could be longer or shorter than on another occasion. I do not see how this is possible, given that we have no other standard clock that can serve as the temporal paradigm. ${ }^{13}$ Were it possible, there would 12 One might find this quite unacceptable, even for an argument. Pure passage is by definition divorced from any physical change. To introduce a clock and its big hand in this crucial (albeit metaphorical) manner seems to defy the definition of pure passage. To this objection, I answer that using the image of the clock of pure passage is justifiable on the basis that we often use imperfect drawings that represent various geometrical figures to understand them. Without any direct contact with pure passage, one can still understand the idea through imagination.

13 I do not think that pure passage automatically precludes well-known relativistic effects such as time dilation. Remember that pure passage is external to any physical 
be no point in positing pure passage: it is posited to serve as the paradigm for making intelligible the statement that a given physical process (our clock or the sun) keeps the 'correct' (or 'incorrect') time, which would be complete nonsense if pure passage itself were unstable. ${ }^{14}$ Just as one metre could not possibly be longer or shorter than what it is, neither could one HOUR be longer or shorter than what it is in pure passage. ${ }^{15}$

If this is correct, pure passage is very peculiar indeed. To see why, take any physical clock around you and consider the statement that

- it takes the amount of time it actually takes on a particular occasion for the big hand

process. Pure passage, unlike time measured in physical terms, cannot speed up or slow down if it is to serve as the temporal paradigm. Having said this, I do think that defenders of the pure passage theory should say something more to cope with problems related to physics.

${ }^{14}$ Saying that pure passage is posited would imply that we could have posited something else. To be certain, pure passage may not necessarily exist because there are alternative views on time that posit no such entity, but it is still true that in the pure passage theory, necessarily, one HOUR is one HOUR. The claim is only that for any world w, if pure passage exists at w, one HOUR is one HOUR at w.

15 For this reason, I disagree with Skow, who says that, '[o]ne could formulate the theory so that the NOW [that is, pure passage of time] sped up, slowed down, and (occasionally) stopped' (2011: 228). He may be right in saying that, '[1]ogic alone does not force moving spotlight theorists to say that the NOW always moves' (Skow 2011: 228)), but to think that the NOW could speed up or slow down would damage the virtue of the pure passage theory, as I have argued. Elsewhere, Skow [2012b] presents a new version of the moving spotlight theory which explains both why the NOW moves and why it moves at a constant rate. 
on the clock to go round.

This statement is clearly an instance of the contingent a priori because it is possible for the clock to go wrong. Furthermore, it is at least conceivable that all physical processes systematically speed up or slow down with respect to pure passage. (It is a sceptical consequence of the pure passage theory that what took an HOUR yesterday may actually take two HOURS today even though we could never notice this. The theory seems to allow such a possibility.) Any clock can be chosen as a temporal standard, just as the stick in Paris serves as the metre standard, but no physical clock can be identified with pure passage itself.

By contrast, to even imagine that pure passage speeds up or slows down is to abandon the very idea. Thus, pure passage (if it exists) has a special status among other changes, just as metre length does among other lengths that physical objects actually have. Unlike the stick in Paris, it is necessary and a priori that

- one metre is (always) one metre.

Similarly, unlike ordinary clocks around us, it is necessary and a priori that

- one HOUR is (always) one HOUR.

Hence, it never fails to take one HOUR for one HOUR to pass, which is just another 
way of saying that necessarily time passes at the rate of one HOUR per HOUR (if this is a permissible thing to say). If so, the question of how fast time passes is no more sensible to ask than how long one metre is. The answers to both questions are instances of the necessary a priori and are therefore tautological or meaningless in the sense that they cannot be false. ${ }^{16}$

16 One might think that if one HOUR indicates something similar to "the amount of time it takes for the big hand on the clock of pure passage to go round', the above sentences would imply the trivial truth that any amount of time is equal to itself. This does not really demonstrate the contrast between the clock of pure passage and ordinary clocks as it is similar in both. In response, I assert that although it is inconsequentially true that the amount of time it takes for a big hand on a clock to go round in a particular occasion is the amount of time it takes for the big hand to go round in that occasion, the substantial claim is that the amount of time it takes for a big hand on a clock to go round in a particular occasion is equal to the amount of time it takes for the big hand to go round in any occasion. This claim should only be true of pure passage. Relatedly, it is not quite correct to say that one HOUR is (always) one hour long, where "one hour" is the unit of time and that what cannot happen with the clock of pure passage is for its big hand to take more or less time than one hour to go round (because the big hand is the ultimate measure of that unit of time). This way of perceiving the matter seems to assume some independent time unit other than that given by pure passage. When I define one HOUR, I mean to say that not only is pure passage absolutely constant but 


\subsection{Another Failure of the Rate Argument: Paradigms and Tautologies}

It is arguable whether it is permissible to ask a question whose answer is necessary and a priori. I tend to agree that one is permitted to ask any question one likes. It can be asked, for instance, how long one metre is, what shape the universal circle has, whether the universal red is red, and so on, however boring it is to answer such questions. In particular, it can be asked how fast time passes, even though the answer is necessary and a priori. The fact that necessarily time passes at the rate of one HOUR per HOUR would not automatically make it unintelligible to ask how fast time passes. ${ }^{17}$ (If the rate of one HOUR per HOUR causes a problem, one may instead say that it takes one HOUR for one HOUR to pass, just to avoid talking of such a rate.)

Alternatively, one may think that any sentence is tautological or meaningless when it is necessary and a priori and that we cannot ask any question whose answer is tautological or meaningless. In this case, however, it is far from clear whether the rate argument succeeds. Because any sentence that appropriately specifies the rate of pure

also incessantly produces the standard time unit itself.

17 Maudlin (2007) and Raven (2011) also think that the fact that a rate is necessary does not thereby make it incoherent. It is coherent that, necessarily, the rate of time's passage is one second per second. They support this claim by giving examples, such as fair currency exchange at the rate of one unit of currency per unit of the same currency and the mathematical constant $\pi$. 
passage to itself is necessary and a priori, defenders of the pure passage theory may simply respond that the rate argument poses a nonsense question that need not be answered. Once this response is accepted, the rate argument cannot even lift off the ground, as Markosian suggests.

Price argues in the opposite direction on the same basis. He claims that we should reject the idea of the passage of time rather than the rate argument and says that, '[i]f it made sense to say that time flows then it would make sense to ask how fast it flows, which doesn't seem to be a sensible question' (Price 1996: 13). To support the claim that it would not make sense to ask how fast time flows, he adds that any question about a rate will become vacuous or uninformative when the two amounts that appear in the rate are the same (Price 2011). In effect, he argues $\left(i^{*}\right)$ that if it made sense to say that time passes, there should be a non-tautological or meaningful answer to the question of how fast time passes, but (ii*) there is no such answer. ${ }^{18}$

I take what happens here to be a reductio ad absurdum, which shows that Price's conditional claim (i*) should be rejected. Time may flow as long as there is such a thing as pure passage, whatever it is. However, I agree that the premise ( $\left.\mathrm{ii}^{*}\right)$ is sound because,

18 Here, we are shifting from the original rate argument to its slightly modified form. The initial question is whether time can pass with or without rate, whereas the present question is whether it makes sense to say that time can pass with or without rate. Mazzola (2014) also notices this subtle difference. For the present purpose, we need not enter into details. 
in pure passage theory, any answer to the question 'how fast does time pass?' is in fact tautological or meaningless (vacuous or uninformative, in Price's terminology). I then conclude that time may flow even if we cannot sensibly ask how fast it flows. To confirm this, consider an analogous argument to that pertaining to metre length. No one would deny that one metre itself has a length: necessarily, one metre is one metre long. Hence, it would not make sense to ask how long one metre is if we cannot ask a question whose answer is tautological or meaningless. Nonetheless, this would not preclude the existence of metre length. It is wrong, then, to assume that if it makes sense to say that one metre has a length, it would make sense to ask how long it is. One metre has a length even if we cannot sensibly ask how long it is.

If the reader wishes to reflect on another example, consider the following argument against universalism. If the universal circle has a shape, there should be a non-tautological or meaningful answer to the question about its shape; but there is no such answer because it is necessary and a priori that the universal circle is circular; and therefore it has no shape. Facing this objection, should universalists give up on the claim that the universal circle has a shape? I say they should not. This suggests that Price's argument proves too much. If accepted, it would refute not only realism about pure passage but also universalism about other paradigms such as length, shape and so on.

\subsection{Scope of the Response}

I have discussed how to amend the flaw in Markosian's argument. The conclusion is 
that time may pass, whether or not we can meaningfully ask how fast it passes. One might complain that I have rendered the question metaphysically uninteresting. It may be said that I confuse the question of how fast time passes with, for instance, how much later it will be an hour from now (or simply how long one hour is). The latter question has nothing to do with the passage of time. If it matters, it matters for any theory that posits external time that may or may not pass. The rate argument, however, is supposed to refute the dynamic view of time that involves the very idea that time passes. The spatial analogy to which I have referred suggests that I fail to address the correct question. Something may be amiss. (I imagine this is an objection that Skow [2011] would raise to my response.)

In reply, I say that to ask how fast time passes is to ask how much later it will be an hour from now. To be certain, the rate argument is supposed to refute the idea of the passage of time, but, for any rate of change, all we can do is measure the rate of some quantity resulting from the change in question to the amount of time it takes. There is no other way of measuring the rate of change to pure passage. Therefore, I think that if the question matters, it matters regardless of which view of time one takes. ${ }^{19}$ This

19 There may be differences between the static and dynamic views in how to treat amounts of time. According to the static view, time may be just another dimension analogous to the three spatial dimensions, so that any amount of time is treated as something akin to spatial distance. According to the dynamic view, an amount of time is not like a spatial distance but simply a quantity resulting from real changes, pure 
also indicates that the rate argument fails to attack the target at which it aims. Any theory of time should explain how the notion of rate is to be understood, and this task is quite irrelevant in determining whether and how pure passage is possible.

The passage of time is one thing and the passage of time at some rate is another. By and large, this is true of the two dynamic theories of time that we have discussed. The rate argument is driven by the question of how fast time passes, but fails to defeat the idea that time passes, because time may pass even if we cannot ask its rate meaningfully. I then suggest that objectors to the dynamic theories of time should attack the very idea that time passes, rather than discussing the indirect question of how fast it passes. As for the pure passage theory, however, I have not argued for the existence of pure passage but only pointed out how the rate argument fails. As proponents of the rate argument do not clearly state what pure passage is (because they do not believe in it), it is possible to doubt the efficacy of the argument without arguing for the existence of pure passage. I should be content if I succeed in breaking a conceptual link between time passing and its passing at some rate.

In sum, pure passage (if it exists) should have the following two formal features. First, it is something more than or independent of changes in things, and second, it should neither speed up nor slow down. On the basis of this rough sketch, I have argued that the pure passage theory is also immune to the rate argument. This does not mean passage or changes in things. Keeping this in mind, we may raise the same question about rate of change in either the dynamic or static view. 
that it is safe to think that there is such a thing as pure passage. Pure passage theorists should fully clarify what pure passage is and argue for its existence. I pass this task on to those who find it worth elaborating the theory. Instead, I return to changes in things, of which I have a clear picture, and try to suggest an extension of the Priorian passage theory that can avoid the potential problem that we noticed at the end of section 2 .

\section{Pure Persistence Theory}

If I am correct, the rate argument can refute neither the Priorian passage theory nor the pure passage theory. This nearly completes my response to the rate argument, but I think that there is still something more to say about the Priorian passage theory, which states that the passage of time is nothing more than changes in things. As mentioned at the end of section 2, this theory seems to imply that time cannot pass when nothing changes. If the theory can avoid the rate argument only at the cost of accepting such an obnoxious implication, it may seem unpalatable. To salvage the Priorian passage theory from this problem, I suggest its possible extension in the rest of the paper.

\subsection{Persistence without Change}

To repeat, the problem is that, if the passage of time is nothing more than changes in things, time cannot pass when nothing changes. Some may simply complain that this is counterintuitive. Others may cite Shoemaker's (1969) infamous thought experiment as a counterexample. Shoemaker invites us into an imaginary world that is divided into three regions. Let us call them A, B and C. Periodically, a phenomenon is observed-a 'local 
freeze'-during which all ordinary changes occurring in one of the three regions come to a halt, and this period lasts for one year. No one in a frozen area is aware of the local freeze, but people in an unfrozen area can observe and testify to its occurrence in a different region. In regions $\mathrm{A}, \mathrm{B}$ and $\mathrm{C}$, local freezes occur every third, fourth and fifth years respectively. Simultaneous local freezes have thus been observed in regions A and B, A and C and B and C, every twelfth, fifteenth and twentieth year, respectively. Now, what will happen in all three regions every sixtieth year? The best simple induction suggests that there will be simultaneous total freezes for one year every sixtieth year.

Priorian passage theorists could challenge this argument in many ways. ${ }^{20}$ After all, it is highly controversial whether one should accept Shoemaker's argument. Even if Shoemaker succeeds in showing the possibility of time without change, in my view, it does not directly threaten the core idea of the Priorian passage theory. The argument shows, at best, that persistence without change is possible, and persistence is nothing but an ordinary physical process that defenders of the Priorian passage theory should also take for granted. Moreover, they do, insofar as they believe that something has existed, exists or will exist. It seems that Prior himself can accept both qualitative and non-qualitative changes in things as he talks about the ageing of a thing, although he does not state his view explicitly. If so, a natural extension of the Priorian passage theory would be to identify the passage of time with the persistence of things rather than with qualitative changes in things. Even if Shoemaker is right, Prior may say that things

20 For an elaborated response to Shoemaker's argument, see Warmbrod (2004). 
can persist without any qualitative changes, while maintaining what motivates him to believe in real changes in things.

Admitting that such a shift is legitimate, one may worry that the phrase 'total freeze for one year' would make no sense in Priorian passage theory. This problem may seem to dissolve when we carefully observe how Shoemaker argues for time without change. According to the argument, the best simple induction should lead us to the conclusion that a total freeze will occur for one year every sixtieth year. By this reasoning, it may only be assumed that the time unit 'year' is already fixed in terms of some reliable physical process in an unfrozen area for an unfrozen period: no external time or pure passage would be required. To put it differently, let us consider the following question: were we inhabitants of Shoemaker's frozen world, should we draw the same inference from the same empirical evidence without invoking any external time? It seems that we should if the induction is to be conducted on empirical basis alone.

As for Shoemaker's original argument, this line of thought may seem plausible, but here is another case in which it does not work. If Shoemaker's story gives us a reason to endorse the possibility of time without change, some form of analogous story could be constructed that would lead us to the possibility of everything periodically speeding up and/or slowing down. In that case, how can we fix the relevant time unit? Moreover, the following simple story could also be told. Suppose that there were no regular cyclic process that could be used as a reliable clock in the universe: just a lot of changes would happen, but no regular processes could be synchronised with one 
another. In Prior's view, time should pass in such a world because things change. Nonetheless, no one can tell how fast time passes (that is, how fast things change) since there is no physical clock with which we can measure a rate of change. ${ }^{21}$

\subsection{Pure Persistence as the Temporal Standard}

Priorian passage theorists could reasonably respond that there would be no fact of matter about how fast things change in the above cases, but they might look for another approach to the problem. In the discussion above, it is still assumed that an amount of time during which things persist should be measured in terms of their qualitative changes, but this assumption can be rejected. If one is ready to accept the Quinean dictum that existence is a precondition for property possession, it should also be admitted that the persistence of things is a precondition for their qualitative change, but not vice versa. While it is undeniable that qualitative changes in things require an amount of time, there is no guarantee that an amount of time during which things persist can always be measured in terms of their qualitative change.

Let us call the persistence of things without any qualitative changes their 'pure persistence'. I then suggest that pure persistence of things be the standard for every rate

21 Priorian passage theorists can no doubt adopt the clock-law account of time measurement suggested by Warmbrod (forthcoming). However, there may be a case where things change (and therefore time passes) but no such account is available. This will happen when no regular process is observed anywhere for any period. 
of change. Pure persistence is the most stable kind of change, and it is at least maintainable that it can never speed up or slow down. Here is a reason for this. First, the possibility of time without change does not imply that of time without persistence, unless one also believes in the existence of a 'temporal vacuum', a period during which nothing exists. None of the cases we have encountered establishes its existence. Nor do they show that pure persistence of things can sometimes be faster or slower. While it may be possible to think that things could persist and instantiate properties at different rates with respect to some external time, it is equally possible to think that things persist stably while instantiating properties at different rates with respect to their persistence. I call the latter view the pure persistence theory and explicate its important features in what follows.

It may be said that the pure persistence of things cannot be observed directly by beings like us, who can only confirm it through their qualitative changes. Therefore, pure persistence of things is ideal in the sense that it rests upon the idea that things persist stably on every occasion. However, the notion of pure persistence should not be rejected only because it is ideal. Any kind of external time (pure passage or whatever) should also have such an ideal aspect. If any of the troublesome cases mentioned previously is really possible, this in turn gives us a reason to think that there should be something absolutely stable that may or may not be detected through the sensory apparatus. A fortiori, there must be such a temporal standard to make sense of those cases.

Keeping this in mind, I also think that the pure persistence theory is less 
ontologically extravagant than any other theory that posits external time, because it adds no extra ingredient to the world. In fact, the temporal standard need not be external time. What is needed is something absolutely stable, and pure persistence of things is expected to do the very job. When it is legitimate to say that something is absolutely stable, this is not because it is stable in relation to some other standard. Something can be taken as absolutely stable, even when no other standard exists, and this makes it the standard. Were this incorrect, another standard would have to be introduced so as to say that the original standard is stable, and this process would never end. It is then easy to see that not only pure persistence theorists but also pure passage theorists would fall into an infinite regress. To avoid such a regress, they should say that their temporal standard is stable in itself. If it is pure persistence of things that is absolutely stable, no external time is required.

If pure persistence is absolutely stable and can serve as the temporal standard, a metric unit of time can be given in the following way. Take any amount of time during which things persist and call it, say, a YEAR. ${ }^{22}$ This time unit may or may not coincide

22 Here I assume the presentist thesis that everything is present and coexists. This assumption may invite a serious challenge from the special theory of relativity (STR). However, it is arguable whether the notion of absolute simultaneity defined in terms of past, present and future coexistence can be rejected by relativity of simultaneity in STR so easily. For relevant discussions, see Prior (1970, 1996), Markosian (2004: 73-5) and Zimmerman (2011). Note that pure passage theorists who believe in absolute 
with what is meant by a 'year' in ordinary talk, but that is irrelevant for the present purpose. The point is that

- necessarily, things persist stably, say, a YEAR per YEAR.

That is to say, anything must grow a YEAR older every YEAR. This is just what pure persistence means. One might object that the phrase 'a YEAR per YEAR' would not make sense because it is tautological or meaningless. Even if this objection is correct, however, pure persistence theorists may at least hold that things persist and that their persistence is absolutely stable, without bothering about its rate. Moreover, if pure passage theorists can avoid the tautology objection, as we have discussed in the previous section, pure persistence theorists can also respond to it in the same way: either that, if the question of how fast things persist is not a sensible thing to ask, the objection cannot lift off the ground, or that things persist stably whether or not we can meaningfully ask their rate, in which case the objection also fails.

By contrast, the same cannot be said of qualitative changes in things. That is, it is not the case that

- necessarily, the second hand on my wristwatch moves one notch every SECOND, simultaneity also face the same problem. I cannot address this issue here due to the space constraints. 
where the referent of a 'SECOND' is fixed by the movement of the wristwatch on a particular occasion. This is not simply because my wristwatch may sometimes go wrong. The statement that the second hand on my wristwatch moves one notch every SECOND can only be contingently true if things may fail to change regularly in their qualities, as the problematic cases show. However, it is still true to say that the wristwatch grows a SECOND older every SECOND as long as it exists. Generally speaking, any sentence that specifies the rate of qualitative changes in things to their pure persistence is contingent, while any sentence that specifies the rate of non-qualitative changes in things to their pure persistence is necessary (and a priori): for pure persistence of things is just a generic name for non-qualitative changes in things.

It seems that Prior could adopt the notion of pure persistence (if he wished) because it does not falsify his belief that the passage of time consists in changes in things. However, I am not quite sure whether Prior himself holds the pure persistence theory or the original passage theory (that is, what I call the Priorian passage theory). One reading of his writings may suggest that he holds the former, but other readings may not. I cannot decide which position he actually takes. If the pure persistence theory is a more accurate description of his view, I admit that the label of 'the Priorian passage theory' would be misleading. (In this case, the original theory should be called the naive Priorian passage theory.) Nevertheless, both theories are Priorian in a broad sense, and I can see nothing in the former that falsifies the latter. Because what is essential to Prior's view is that the passage of time consists in changes in things, the pure persistence theory 
is a simple extension of the Priorian passage theory. I also think that the ideal aspect of pure persistence (that is, its absolute stability) will not cause a problem if the pure passage theory can avoid the tautology objection. I then conclude that there is no worry about the rate argument for pure persistence theorists. ${ }^{23}$

\section{Conclusion}

I have argued that the three passage theories examined here are all defensible against the rate argument on slightly different grounds. Each theory may have its own problem, but the rate argument has no bearing on the discussed subject. It is ineffective because time may pass with or without rate, whatever 'the passage of time' means.

\section{Acknowledgement:}

An earlier version of the paper was presented at the international workshop 'A Frontier of Philosophy of Time' held at Kyoto University in 2013. I thank the participants and audience for the helpful discussion. I also thank Seahwa Kim and Takashi Yagisawa for

${ }^{23}$ Pace Tallant (2010: esp. 138), I think that a denial of the possibility of time without change (more properly, persistence without change) is not a consequence of presentism itself, but of some other premise. Even Priorian passage theorists need not claim that changes in things must occur at any world, but it is enough to say that things can undergo such changes. Sakon (2015) offers such a dynamic version of presentism. Having said this, I think that a part of the disagreement between Tallant and me can be resolved once it is noticed that pure persistence may count as (non-qualitative) changes in things. 
their kind comments and suggestions. Finally, many feedbacks from the anonymous referees of this journal helped me to improve the paper to a great degree. This work was supported by JSPS KAKENHI Grant Number 16K16682. 


\section{References}

Hinchliff, M. (1996). The puzzle of change. In J. Tomberlin (Ed.), Philosophical Perspectives 10 (pp. 119-36). Cambridge, MA: Blackwell.

Kripke, S. A. (1980). Naming and necessity. Cambridge: Harvard University Press. Markosian, N. (1993). How fast does time pass? Philosophy and Phenomenological Research, 53, 829-44.

Markosian, N. (2004). A defense of presentism. In D. W. Zimmerman (ed.), Oxford Studies in Metaphysics, Vol. 1 (pp. 47-82). Oxford: Clarendon Press.

Maudlin, T. (2007). The metaphysics within physics. Oxford: Oxford University Press.

Mazzola, C. (2014). Does time follow, at any Rate? Metaphysica, 15, 157-72.

Merricks, T. (1994). Endurance and indiscernibility. Journal of Philosophy, 91, 165-84.

Olson, E. T. (2009). The rate of time's passage. Analysis, 69, 3-9.

Phillips, I. (2009). Rate abuse: a reply to Olson. Analysis, 69, 503-5.

Price, H. (1996). Time's arrow and archimedes' point: New Directions for the Physics of Time. Oxford: Oxford University Press.

Price, H. (2011). The flow of time. In C. Callender (Ed.), The Oxford Handbook of Philosophy of Time (pp. 276-311). Oxford: Oxford University Press.

Prior, A. N. (1958). Time after time. Mind, 67, 244-6.

Prior, A. N. (1962). Changes in events and changes in things. In P. Hasle, P. Øhrstrøm, T. Braüner, \& J. Copeland (Eds.), Papers on time and tense (new edition 2003; pp. 7-19). Oxford: Oxford University Press.

Prior, A. N. (1970). The notion of the present. Studium Generale, 23, 245-8. 
Prior, A. N. (1996). Some free thinking about time. In J. Copeland (ed.), Logic and Reality: Essays on the Legacy of Arthur Prior (pp. 47-51). Oxford: Oxford University Press.

Raven, M. J. (2011). Can time pass at the rate of 1 second per second? Australasian Journal of Philosophy, 89, 459-65.

Sakon, T. (2015). Presentism and the triviality objection. Philosophia, 43, 1089-1109.

Shoemaker, S. (1969). Time without change. Journal of Philosophy, 66, 363-81.

Skow, B. (2012a). One second per second. Philosophy and Phenomenological Research, $85,377-89$.

Skow, B. (2012b). Why does time pass? Noûs, 46, 223-42.

Skow, B. (2011). On the meaning of the question "How fast does time pass?" Philosophical Studies, 155, 325-44.

Smart, J. J. C. (1949). The river of time. Mind, 58, 483-94.

Tal, E. (2011). How accurate is the standard second? Philosophy of Science, 78, 10821096.

Tallant, J. (2010). A sketch of a presentist theory of passage. Erkenntnis, 73, 133-40. Van Inwagen, P. (2009). Metaphysics, 3rd edition. Cambridge, MA: Westview Press. Warmbrod, K. (2004). Temporal vacua. The Philosophical Quarterly, 54, 266-86. Warmbrod, K. (forthcoming). Time, change and time without change. Synthese, 1-21. Williams, D. C. (1951). The myth of passage. Journal of Philosophy, 48, 457-72. Zimmerman, D. (2011). Presentism and the space-time manifold. In C. Callender (ed.), The Oxford Handbook of Philosophy of Time (pp. 163-244). Oxford: Oxford 
University Press. 